This document is confidential and is proprietary to the American Chemical Society and its authors. Do not copy or disclose without written permission. If you have received this item in error, notify the sender and delete all copies.

\title{
Heterogenization of photochemical molecular devices: embedding metal-organic cage into ZIF-8-derived matrix to promote proton and electron transfer
}

\begin{tabular}{|c|c|}
\hline Journal: & Journal of the American Chemical Society \\
\hline Manuscript ID & ja-2019-03981f.R1 \\
\hline Manuscript Type: & Article \\
\hline $\begin{array}{r}\text { Date Submitted by the } \\
\text { Author: }\end{array}$ & 28-Jun-2019 \\
\hline Complete List of Authors: & $\begin{array}{l}\text { Luo , Yu-Cheng ; Sun Yat-Sen University, School of Chemistry } \\
\text { Chu, Kun-Ling; Sun Yat-Sen University, School of Chemistry } \\
\text { Shi, Jian-Ying; Sun Yat-Sen University, School of Chemistry } \\
\text { Wu, Dong-Jun ; Sun Yat-Sen University, School of Chemistry } \\
\text { Wang, Xu-Dong; Sun Yat-Sen University } \\
\text { Mayor, Marcel; Universitat Basel, Department of Chemistry; Sun Yat-Sen } \\
\text { University, Lehn Institute of Functional Materials, School of Chemistry } \\
\text { Su, Cheng-Yong; Sun Yat-Sen University, School of Chemistry }\end{array}$ \\
\hline
\end{tabular}

\section{SCHOLARONE ${ }^{m}$ Manuscripts}




\section{INTRODUCTION}

Artificial photosynthesis, taking nature as an example by manipulating light-harvesting antennae and catalytic centers to fulfil solar-to-fuel conversion directly and efficiently, provides an attractive solution for large-scale energy storage and usage. ${ }^{1-3}$ Photochemical molecular devices (PMDs), organizing chromophoric photosensitizer, catalytic center and electron relay in a molecular level, is competent for efficient electron and energy transfer in photocatalysis, reminiscent of collaborative and synergistic functions in photosystems I and II. ${ }^{4-8}$ However, the development of PMDs for practical applications still faces challenges including: (1) proper organization of multiple photosensitizing and catalytic centers in one PMD while maintaining efficient and directional electron transfer, since at least two electrons have to be consumed in $\mathrm{H}_{2}$ formation, and (2) circumventing the vulnerability of molecular catalysts under harsh photocatalytic conditions. We have developed a bimetallic $\left[\mathrm{Pd}_{6}\left(\mathrm{RuL}_{3}\right)_{8}\right]^{28+}(\mathrm{L}=2$ (pyridin-3-yl)-1H-imidazo [4,5-f][1,10]-phenanthroline) metal-organic cage (MOC-16) as a new type of PMDs to unify multiple photosensitizing, electron relay and catalytic units in a highly symmetrical way to achieve directional and independent multichannel electron transfer for efficient $\mathrm{H}_{2}$ generation; 5,9 nevertheless, photodegradation and detrimental aggregation of dissociated Pd particles after a long-time irradiation is still inevitable in homogenous photocatalysis.

Another strategy of artificial photosynthesis is based on heterogeneous catalysts, of which metal-organic frameworks (MOFs) with merits of structural regularity and synthetic tunability provide a versatile platform to hierarchically organize light-harvesting antennae and/or catalytic centers by virtue of purposely engineering coordination chemical nanospace. ${ }^{10-12}$ Various molecular catalysts and/or photosensitizers have been integrating into MOFs as inorganic nodes, organic linkers or included guests for water photosplitting, ${ }^{13,14} \mathrm{CO}_{2}$ photofixation and organic photosynthesis. ${ }^{15}$ For example, by utilizing free $\mathrm{Ru}(\mathrm{bpy})_{3}{ }^{2+}$ as photosensitizer, Mn-bipyridine or $\left[\mathrm{Fe}_{2} \mathrm{~S}_{2}\right]$ 
Scheme 1. The process to incorporate MOC-16 into ZIF-8 matrix via coordination-assisted secondary assembly followed by transforming ZIF-8 structure to CZIF-matrix in the presence of $\mathrm{CO}_{2}$ and water.

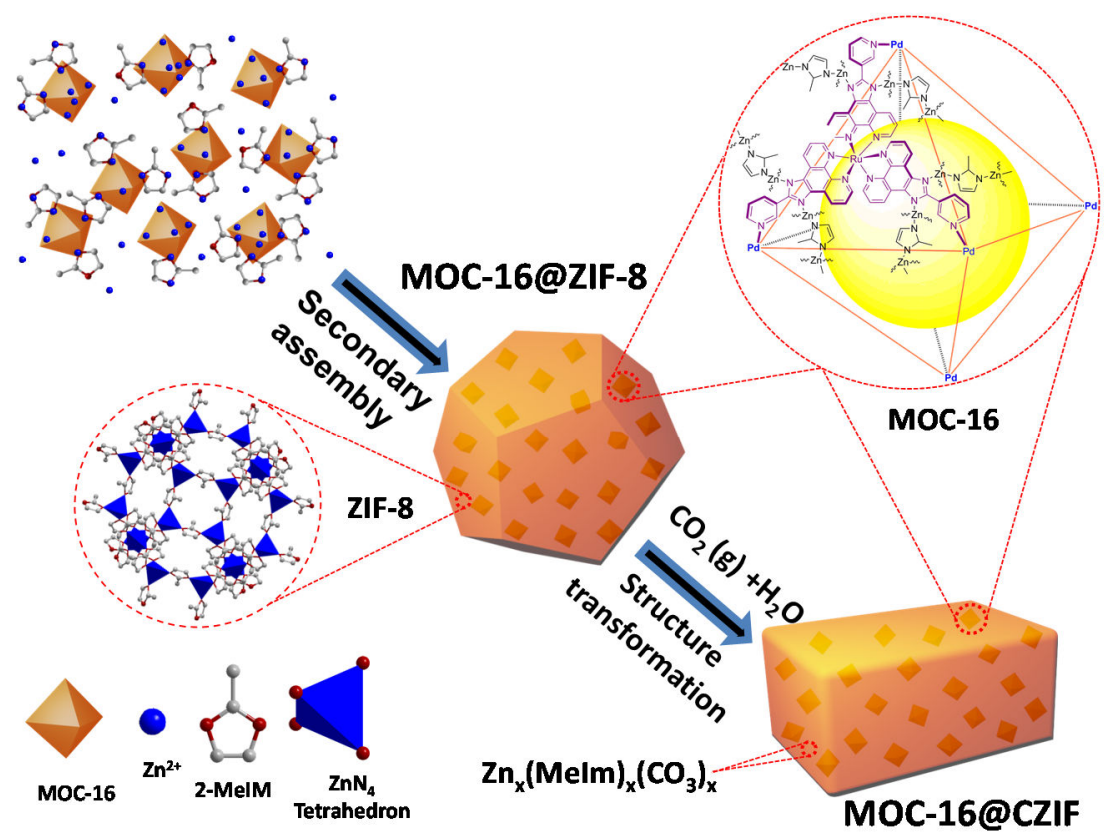

based catalysts were anchored onto organic linker of UiOMOF for proton and $\mathrm{CO}_{2}$ reduction. ${ }^{16,17}$ Moreover, cobaloxime catalyst was incorporated into photo-active $\mathrm{NH}_{2}$-MIL-125(Ti), ${ }^{18}$ Pt-nanoparticles (Pt-NPs) were encapsulated into cavities of light-harvesting $\left[\operatorname{Ir}(\text { ppy })_{2}(\mathrm{bpy})\right]^{+}$-derived UiO-MOF, ${ }^{19}$ and a molecular $\mathrm{Pt}^{2+}$ catalyst and an Ir(III) light-absorber were simultaneously embedded in UiO-MOF struts. ${ }^{20}$ These MOF-derived catalysts did show good photoreduction activity compared with their homogenous counterparts, as a result of promoted electron transfer from guest-to-strut, ${ }^{16,17}$ strutto-guest, ${ }^{18,19}$ or strut-to-strut, ${ }^{20}$ but the photoactive centers and the catalytic centers in MOFs are still separated in space and long distance energy migration/electron hopping is challenging due to weak electronic coupling. To overcome these problems, an alternative strategy is to integrate a PMD as whole, which features close vicinity and intramolecular electron transfer between directly bonded photosensitizing and reactive centers, into MOF-matrix to facilitate efficient electron and/or energy transfers for photocatalysis. However, thus far, this type of PMD@MOF photocatalysts remain unexplored. Only resembling examples for proton reduction were found from porphyrinderived MOFs. ${ }^{21,22}$

Since the MOC-type PMD takes an advantage to be able to unify multiple photosensitizing and catalytic units with efficient and directional electron transfer for homogeneous photocatalysis, ${ }^{5}$ we envision that integrating such MOCs into an MOF-matrix could, on one hand, inherit the distinctive photocatalytic feature and, on the other hand, provide a promising strategy to heterogenize PMDs for hetereogeneous photocatalysis to tolerate harsh conditions. Moreover, the MOC@MOF integration may provide a way to adjust electron transfer dynamics via the structural and spatial heterogeneity. The microenvironments in MOFmatrix may also be able to facilitate proton transfer, provide local $\mathrm{pH}$ buffering, regulate ion transport, stabilize catalytic site, and so on, reminiscent of enzymatic-type behaviors. ${ }^{23}$,
Herein, we report a heterogenous PMD@MOF photocatalyst generated by incorporating MOC-16 into a crystalline carbonate $\mathrm{Zn}_{\mathrm{x}}(\mathrm{MeIm})_{\mathrm{x}}\left(\mathrm{CO}_{3}\right)_{\mathrm{x}}$ (defined as CZIF) matrix which is in-situ derived from ZIF-8 in presence of $\mathrm{CO}_{2}$ and water. As expected, the heterogenization imparts the embedded MOC-16 PMDs with excellent stability, while retaining high-efficient energy and electron transfer. The CZIF-matrix also engenders hydrophilic nature for proton transfer, and prolongs electron lifetime in excited-states, leading to a synergistic effect for 50 -fold improvement of turnover frequency (TOF) in contrast to homogenous MOC16 in photocatalytic $\mathrm{H}_{2}$ generation.

\section{RESULTS AND DISCUSSION}

Design strategy. As mentioned above, the synthetic methods to incorporate molecular catalysts and/or photosensitizers into MOFs have been vigorously explored in recent years, including the mixed-ligand multivariate approach (MTV), postsynthetic exchange (PSE), sequent postsynthetic metalation (PSM), ${ }^{16-18,20,21,24}$ as well as recent Lin`s work by directly incorporating catalyst in the secondary building units (SBUs) of photosensitizing MOFs. $^{22}$ These heterogenization approaches are usually applicable to molecular catalysts and/or photosensitizers with small size. By contrast, MOC-16 comprises eight RuL 3 photosensitizers and six $\mathrm{Pd}^{2+}$ catalytic centers to form huge $\left[\mathrm{Pd}_{6}\left(\mathrm{RuL}_{3}\right)_{8}\right]^{28^{+}}$octahedral cage with the diameter of $\sim 3 \mathrm{~nm}$ and a cavity of $5350 \AA^{3} .{ }^{9}$ Therefore, the post-modification or "ship-in-a-bottle" strategies to introduce MOCs into MOFmatrix is infeasible as limited by the pore size. Alternatively, a "bottle-around-a-ship" strategy, namely, secondary assembly of MOF on MOC outside surface, is more prone to realize their integration, analogous to our previous intercalation of $\mathrm{Au}_{25}$ (SG) 18 into ZIF-8 scaffolds. ${ }^{25}$ A synthetic process of heterogenizing MOC-16 through coordinationassisted secondary assembly is illustrated in scheme 1, where MOC-16@ZIF-8 precursors are initially grown from a mixture of MOC-16, $\mathrm{Zn}^{2+}$ and 2-MeIm subcomponents by 


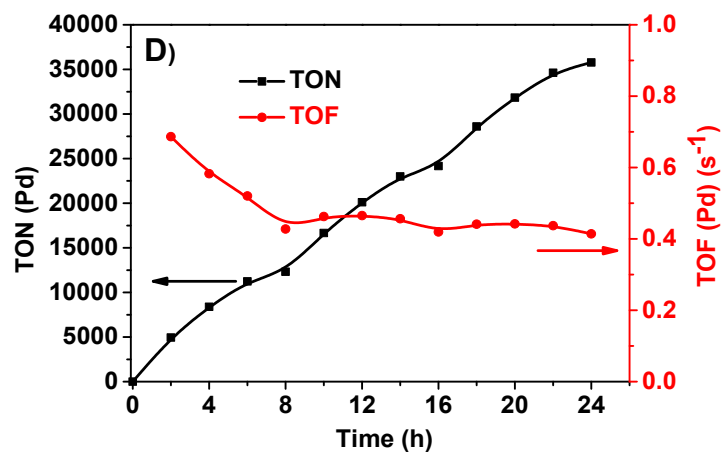

Figure 1. $\mathrm{H}_{2}$ evolution curves with prolonging irradiation time for MOC-16@CZIF photocatalyst under $\mathrm{N}_{2}$ and $\mathrm{CO}_{2}$ atmosphere. A) first cycle run; B) second cycle run; C) third cycle run, and D) accumulated TONs and TOFs based on Pd-center in catalyst durability test over $24 \mathrm{~h}$ under $\mathrm{CO}_{2}$ atmosphere. TON $=n\left(\mathrm{H}_{2}\right) / n(\mathrm{Pd})$, TOF $=d_{(\mathrm{TON})} / d_{\mathrm{t}}$. Visible-light $(\lambda>420 \mathrm{~nm})$ irradiating with $100 \mathrm{~mW} / \mathrm{cm}^{2}$ intensity.

virtue of $\mathrm{Zn}-\mathrm{N}$ coordination linkage between the imidazole rings of MOC-16 and the 2-MeIm ligands. Such MOC16@ZIF-8 precursors are apt to aggregate via epitaxial growth or oriented attachment, induced by surface intension, to lead to crystallization of hybridized MOC@MOF. ${ }^{26,27}$ Since ZIF-8 crystals are known reactive to $\mathrm{CO}_{2}$ under moisture or liquid water conditions to cause chemical degradation, ${ }^{28}$ a following in-situ structural transformation of ZIF-8 from $\mathrm{Zn}(\mathrm{MeIm})_{2}$ to carbonate $\mathrm{Zn}(\mathrm{MeIm})_{2} \cdot \mathrm{Zn}\left(\mathrm{CO}_{3}\right)_{2} \cdot 0.66 \mathrm{HMeIM}$ (CZIF) in the presence of $\mathrm{H}_{2} \mathrm{O}$ and $\mathrm{CO}_{2}$ is carried out, finally giving rise to MOC16@CZIF. This transformation from ZIF-8 to carbonate CZIF has been reported to originate from partial substitution of MeIm by $\mathrm{CO}_{3}{ }^{2-}$ carbonate, ${ }^{28}$ while the integrated MOC- 16 in the CZIF scaffold is well retained.

$\mathbf{H}_{2}$ production. The photocatalytic $\mathrm{H}_{2}$ evolution has been evaluated by visible light irradiation $(\lambda>420 \mathrm{~nm})$ in the presence of sacrificial agent of 1,3-dimethyl-2-phenyl-2,3dihydro-1H-benzimidazole (BIH) in a mixed solvent of $\mathrm{H}_{2} \mathrm{O}$ and $\mathrm{MeCN}(\mathrm{v} / \mathrm{v}=2 / 3)$ under $\mathrm{N}_{2}$ or $\mathrm{CO}_{2}$ atmosphere. For the pristine MOC-16@ZIF-8 catalyst, only trace $\mathrm{H}_{2}$ is detected under $\mathrm{N}_{2}$ atmosphere; however, remarkable $\mathrm{H}_{2}$ evolution is observed in the presence of $\mathrm{CO}_{2}$ (Figure S1). The X-ray diffraction (XRD) structural characterization of the recovered catalyst indicates that ZIF-8 matrix in MOC16@ZIF-8 has been simultaneously transformed to CZIF in photocatalytic process, which is consistent with the literature that ZIF-8 is sensitive to $\mathrm{CO}_{2}$ in $\mathrm{H}_{2} \mathrm{O}$ environment. ${ }^{28}$ Therefore, prior to photocatalytic reaction, the pristine MOC-16@ZIF-8 was changed to MOC-16@CZIF to evaluate the $\mathrm{H}_{2}$ generation performance. As shown in Figure 1, almost same $\mathrm{H}_{2}$ evolution curves are obtained under $\mathrm{N}_{2}$ and $\mathrm{CO}_{2}$ atmosphere for MOC-16@CZIF. The $\mathrm{H}_{2}$ output after $8 \mathrm{~h}$ reaches up to $\sim 32 \mathrm{mmol} \cdot \mathrm{g}^{-1}$, corresponding to complete consumption of $\mathrm{BIH}$ as a one-electron donor. The accumulated turnover number (TON) based on Pdcenters is $\sim 12317$ in $8 \mathrm{~h}$, and the instantaneous TOF at $8 \mathrm{~h}$ is estimated for $0.43 \mathrm{H}_{2} \mathrm{~S}^{-1}$, both of them are far higher than homogenous MOC-16 system of $635(48 \mathrm{~h})$ and $30 \mathrm{H}_{2} \mathrm{~h}^{-1}$ in our previous work. ${ }^{5}$ Table $\mathrm{S} 1$ summarizes the $\mathrm{H}_{2}$ generation results under various experimental conditions over $8 \mathrm{~h}$ irradiation, in together with the control experimental results. In the absence of MOC-16 or BIH (entries 5 and 6), no $\mathrm{H}_{2}$ evolution is detected, confirming that the PMD of MOC-16 and sacrificial agent are indispensable for $\mathrm{H}_{2}$ generation. The light on/off curve further indicates that $\mathrm{H}_{2}$ evolution is a photochemical process initiated with light irradiation (Figure S2). The dosages for the photocatalyst and BIH are optimized as shown Figure S3, indicating a preferable catalytic condition: 1 mg MOC-16@CZIF photocatalyst in $5 \mathrm{~mL} \mathrm{H}_{2} \mathrm{O}-\mathrm{MeCN}(\mathrm{v} / \mathrm{v}=2 / 3)$ mixture containing $14 \mathrm{mg}$ sacrificial agent of BIH. It should be mentioned that only minimal amount of $\mathrm{CO}$ and $\mathrm{HCOOH}$ is detected for MOC-16@CZIF catalyst after $8 \mathrm{~h}$ lightirradiation (Table S1), irrespective of $\mathrm{CO}_{2}$ or $\mathrm{N}_{2}$ atmosphere and $\mathrm{H}_{2} \mathrm{O}$ presence. These results indicate that MOC16@CZIF is not competent for $\mathrm{CO}_{2}$ reduction, thereof showing high $\mathrm{H}_{2}$ evolution selectivity. It is also noticeable that, although a basic solvent mixture of DMSO/ $\mathrm{H}_{2} \mathrm{O}$ with TEOA as sacrificial agent is preferred for the homogeneous $\mathrm{H}_{2}$ production with MOC- $16,{ }^{5}$ a slightly acidic reaction condition in presence of $\mathrm{CO}_{2}$ is generated $(\mathrm{pH} \sim 6)$ in present case, which makes $\mathrm{BIH}$ as a more suitable sacrificial agent in heterogeneous system MOC-16@CZIF. On the contrary, with BIH as sacrificial agent without protection of CZIF-matrix, the MOC-16 homogenous photocatalyst is apt to reduction to black $\mathrm{Pd}$ in solution, leading to ineffectiveness of $\mathrm{H}_{2}$ evolution (Figure $\mathrm{S} 4$ ).

To test the catalytic durability of the resulting heterogenous MOC-16@CZIF photocatalyst, the sequential reaction-cycles ( $8 \mathrm{~h}$ per cycle) were carried out under both $\mathrm{CO}_{2}$ and $\mathrm{N}_{2}$ atmosphere. As seen from Figure 1, the comparable $\mathrm{H}_{2}$ amount is detected in three cycles under $\mathrm{CO}_{2}$ atmosphere. By contrast, under $\mathrm{N}_{2}$ atmosphere, $\mathrm{H}_{2}$ production falls obviously by almost half in the second run (Figure 1B) and even less in the third run (Figure 1C), although nearly identical $\mathrm{H}_{2}$ evolution is observed in the first cycle as that under $\mathrm{CO}_{2}$ atmosphere (Figure $1 \mathrm{~A}$ ). This means that the presence of $\mathrm{CO}_{2}$ plays an important role to sustain the photocatalytic performance of MOC-16@CZIF. Under $\mathrm{CO}_{2}$ atmosphere, the accumulated TON based on Pdcenter in durability test over $24 \mathrm{~h}$ approaches $\sim 35000$, and

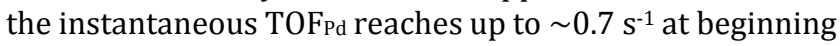
and then maintains at $\sim 0.4 \mathrm{~s}^{-1}$ (Figure 1D).

Mechanism study. A series of controlled experiments have been carried out to unveil photocatalytic nature for $\mathrm{H}_{2}$ evolution under comparable conditions, as depicted in Figure S4. The fragmental analogues of MOC-16, $\mathrm{RuL}_{3}$ and $\mathrm{PdPy}_{4}(\mathrm{Py}=\mathrm{Pyridine})$, were concomitantly embedded into 

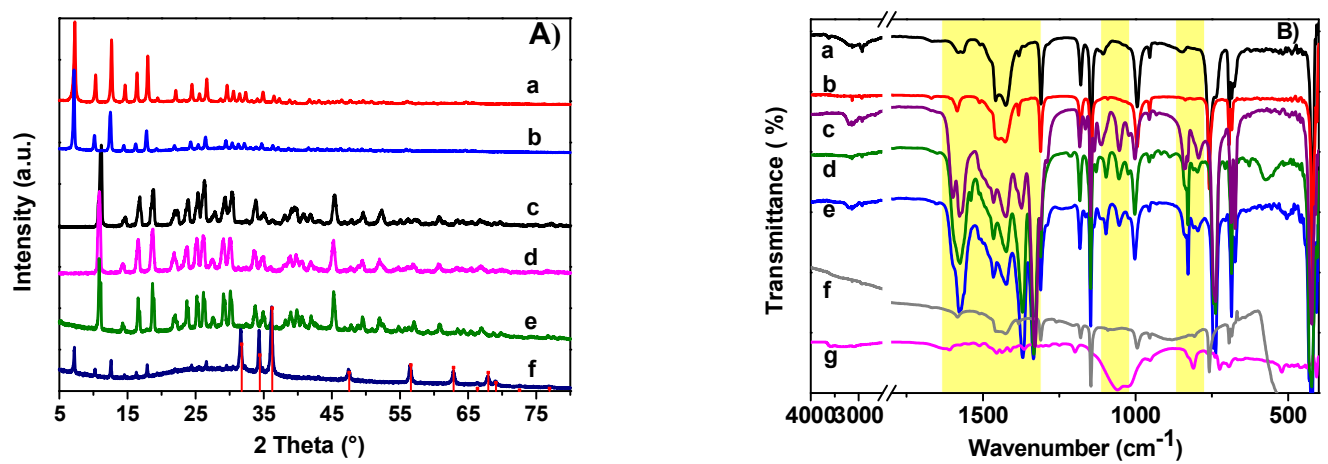

Figure 2. A) XRD patterns and B) IR spectra of MOC-16@MOF photocatalysts. From top to bottom: a) ZIF-8, b) MOC-16@ZIF-8, c) CZIF, d) MOC-16@CZIF, e) recycled MOC-16@CZIF under $\mathrm{CO}_{2}$ atmosphere, f) recycled MOC-16@CZIF under N2 atmosphere and g) MOC-16.

ZIF-8 matrix to give ( $\left.\mathrm{RuL}_{3}+\mathrm{PdPy}_{4}\right) @ \mathrm{ZIF}-8$, or separately incorporated into ZIF-8 matrix in combination with homogeneous $\mathrm{PdPy}_{4}$ and $\mathrm{RuL}_{3}$ to lead to $\mathrm{PdPy}_{4} @ \mathrm{ZIF}$ 8+RuL3 and RuL $3 @$ ZIF-8+PdPy 4 systems, respectively. It is found that, under $\mathrm{CO}_{2}$ atmosphere, when catalytic $\mathrm{PdPy}_{4}$ is embedded in MOF-matrix, $\mathrm{H}_{2}$ generation is achieved, no matter photosensitizer RuL3 is homogeneously dissolved into solvent or heterogeneously embedded into matrix, but lower than half amount of MOC-16@CZIF. For sample of $\mathrm{RuL}_{3} @$ matrix combining homogenous $\mathrm{PdPy}_{4}$, no $\mathrm{H}_{2}$ evolution is detected. In addition, once MOC-16@CZIF is treated with $\mathrm{NaBH}_{4}$ to reduce $\mathrm{Pd}^{2+}$ to $\mathrm{Pd}^{0}$ (verified by XPS in Figure S5), negligible $\mathrm{H}_{2}$ is detectable in $8 \mathrm{~h}$ irradiation. These control experimental results verify that integration of whole MOC-16 as a PMD unit comprising both photosensitizing $\mathrm{RuL}_{3}$ and catalytic $\mathrm{PdPy}_{4}$ fragments is indispensable for the high activity of $\mathrm{H}_{2}$ evolution. The intact MOC-16 structure integrated inside carbonate CZIF has also been confirmed by ${ }^{1} \mathrm{H}$ NMR measurement (Figure S5), where a set of proton peaks belonging to MOC-16 is detected after digesting MOC-16@CZIF.

XRD and Fourier-transform infrared (FTIR) spectra were carried out to characterize structure of heterogenous MOC@MOF catalysts before and after photocatalysis. As shown in Figure 2A, the XRD pattern of synthesized ZIF-8 matches well with literature result. ${ }^{29,30}$ After encapsulating MOC-16 into ZIF-8, the diffraction patterns keep salient and unchanged, indicating good crystallinity of ZIF-8 matrix after integration. The structure transformation of ZIF-8 when treated with $\mathrm{H}_{2} \mathrm{O}$ and $\mathrm{CO}_{2}$ is evident from the well matching profile with the known carbonate $\mathrm{CZIF},{ }^{28}$ which is

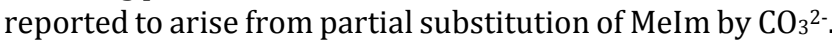
Similarly, when treating MOC-16@ZIF-8 hybrid with $\mathrm{H}_{2} \mathrm{O}$ and $\mathrm{CO}_{2}$, the structural conversion to MOC-16@CZIF is convincing from the identical XRD patterns with CZIF. The recycled MOC-16@CZIF catalyst under $\mathrm{CO}_{2}$ atmosphere retains CZIF-matrix. By contrast, the recycled catalyst under $\mathrm{N}_{2}$ atmosphere degrades to a mixture of ZIF-8 and $\mathrm{ZnO}$ (\#36-1451), suggesting dissociation of $\mathrm{CO}_{3}{ }^{2-}$ from CZIFmatrix in the absence of $\mathrm{CO}_{2}$ feeding. This finding indicates that $\mathrm{CO}_{2}$ is demanding to maintain $\mathrm{Zn}_{\mathrm{x}}(\mathrm{MeIm})_{\mathrm{x}}\left(\mathrm{CO}_{3}\right)_{\mathrm{x}}$ structure. Furthermore, when comparing ZIF-8 with CZIF, or, MOC-16@ZIF-8 with MOC-16@CZIF, obvious variations of IR spectra at 750-850, 1000-1100 and 1300-1650 $\mathrm{cm}^{-1}$ regions are observed (Figure $2 \mathrm{~B}$ ), which are related to carbonate in CZIF as summarized in Table S2. For recycled
MOC-16@CZIF-8 under $\mathrm{CO}_{2}$ atmosphere, IR bands are analogous to those of MOC-16@CZIF, in contrast, recycled MOC-16@CZIF-8 under $\mathrm{N}_{2}$ atmosphere shows characteristic IR bands of ZIF-8. These results unveil that CZIF-matrix remains intact in $\mathrm{CO}_{2}$ atmosphere but degrades back to ZIF-8 in $\mathrm{N}_{2}$ atmosphere without $\mathrm{CO}_{2}$ supplement during photocatalysis. The IR signals relating to MOC-16 (Figure 2B-g) become featureless in MOC-16@MOF samples due to low content of MOC-16, overwhelmed by strong vibrations of 2-MeIm and $\mathrm{CO}_{3}{ }^{2-}$.

In order to discern distribution of MOC-16 in heterogeneous photocatalysis, aberration corrected highangle annular dark-field (HAADF) scanning transmission electron microscopy (STEM) imaging and energydispersive X-ray (EDX) spectroscopy element mapping were performed. Figure 3 gives representative HAADFSTEM images and element maps of MOC-16@ZIF-8 and MOC-16@CZIF. From the element distribution of MOC16@ZIF-8, we can clearly see that both Ru and Pd atoms are homogenously scattered in ZIF-8 matrix (Figure 3g-h) with lower density than $\mathrm{Zn}, \mathrm{C}$ and $\mathrm{N}$ elements (Figure 3b-c, 3f), which verifies that MOC-16 is uniformly encapsulated in the whole ZIF-8 matrix. Similar uniform distribution of $\mathrm{Ru}$ and Pd elements (Figure 3g'-h') in CZIF matrix is observed for MOC-16@CZIF. Therefore, the structural transformation from ZIF-8 to CZIF does not disturb the integrated MOC-16 in MOF-matrix. On the other hand, the obvious densityincrease of 0 elements in MOC-16@CZIF (Figure 3d') in contrast to original MOC-16@ZIF-8 (Figure 3d) is evident, in accordance with appearance of $\mathrm{CO}_{3}{ }^{2-}$ carbonate which is also homogenously dispersed in CZIF-matrix. However, after photocatalytic reaction under $\mathrm{N}_{2}$ atmosphere, the recycled MOC-16@CZIF samples display morphology deterioration obviously (Figure S6), in agreement with the formation of $\mathrm{ZnO} / \mathrm{ZIF}-8$ conglomerates with much loose distribution of corresponding elements.

X-ray photoelectron spectroscopy (XPS) shown in Figure 4 were further carried out to monitor chemical states of Pd and Ru elements in heterogenous MOC@MOF before and after photocatalytic reaction, together with that of MOC-16 for comparison. The binding energy (BE) is calibrated to adventitious carbon $\mathrm{C} 1 \mathrm{~s}$ peak at $284.8 \mathrm{eV}$, and summarized in Table S3. Although Ru 3d overlaps with C 1 s in Figure 4A, $\mathrm{Ru} 3 \mathrm{~d}_{5 / 2}$ at $\sim 280.8 \mathrm{eV}$ (Figure $4 \mathrm{~B}$ ) can be discerned in all samples, which is consistent with $\mathrm{Ru}^{2+}$ oxidation state. ${ }^{31}$ Negligible variety of this peak in four samples indicates that 

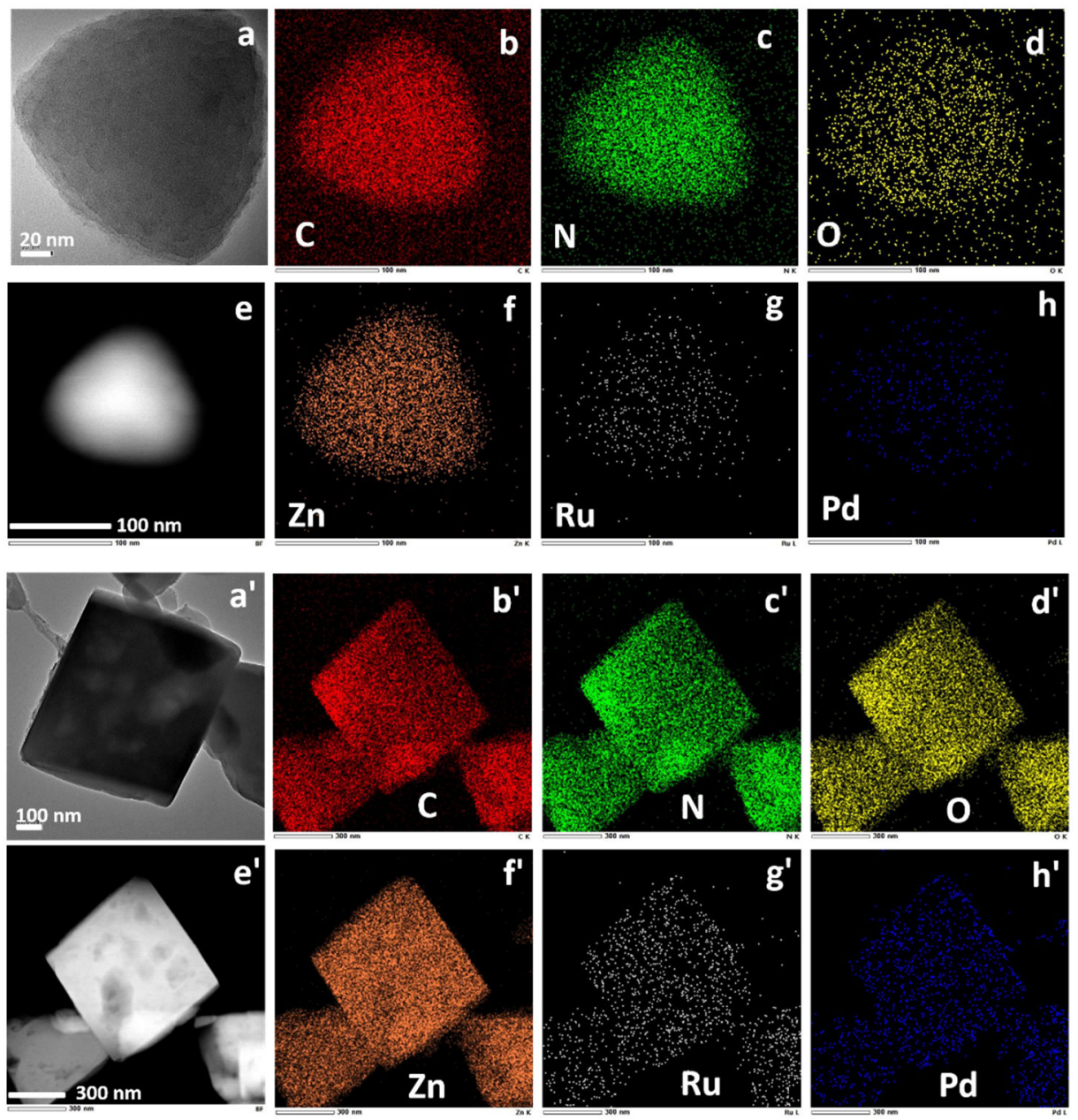

Figure 3. HAADF-STEM images (a, a', e, e') and corresponding elemental maps (b-d, b'-d', f-h, f'-h') of a-h) MOC-16@ZIF-8 and a'-h') MOC-16@CZIF.
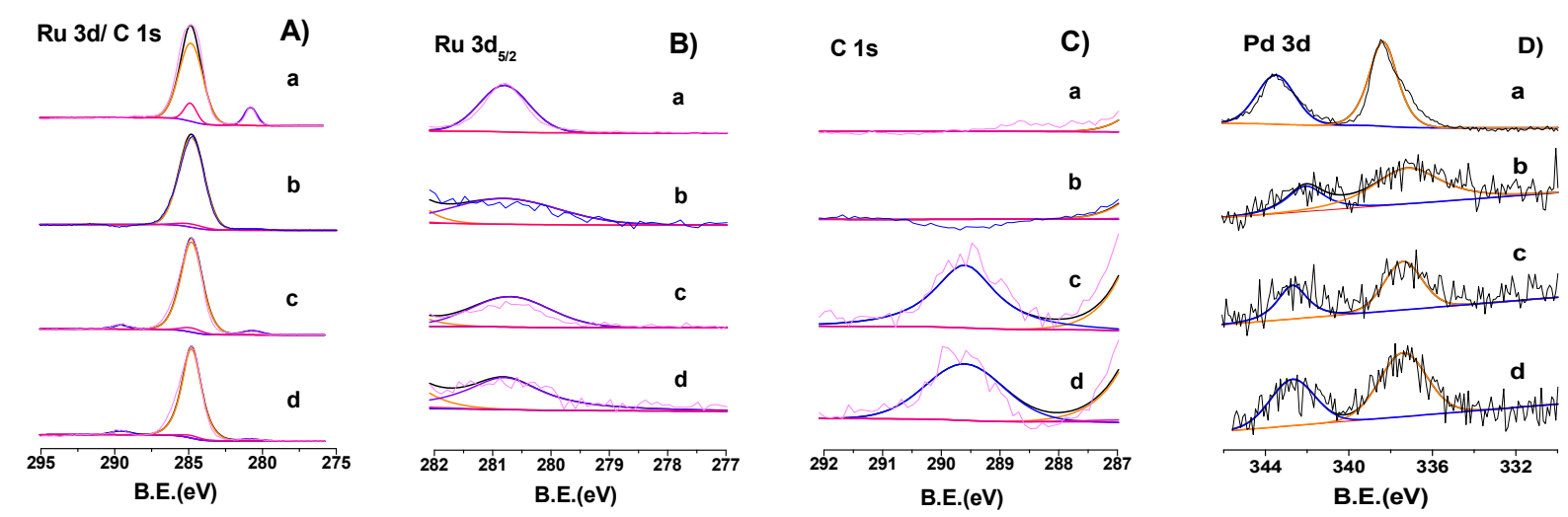

Figure 4. XPS spectra of A) Ru 3d/C 1s, B) Ru 3d5/2, C) C1s and D) Pd 3d in a) MOC-16, b) MOC-16@ZIF-8, c) MOC-16@CZIF and d) recycled MOC-16@CZIF under $\mathrm{CO}_{2}$ atmosphere. Inset in A) is enlarged parts in regions of 282 278 and 292 288 eV.

$\mathrm{Ru}^{2+}$ oxidation state is sustained both in incorporation and photocatalysis processes. Additional peak of C 1 s at 289.6 $\mathrm{eV}$ (Figure 4C) relating to $\mathrm{CO}_{3}{ }^{2-}$ is observed in MOC16@CZIF and recycled sample, ${ }^{32}$ which further proves $\mathrm{CO}_{3}{ }^{2-}$ nature in CZIF-matrix. In Figure 4D, double peaks of Pd corresponding to $3 \mathrm{~d}_{5 / 2}$ and $3 \mathrm{~d}_{3 / 2}$ are observed for all samples. When comparing binding energy, we can find that $3 \mathrm{~d}_{5 / 2}$ peak is shifted from 338.4 to $337.4 \mathrm{eV}$ when incorporating MOC-16 into matrix. It is still higher than binding energy of metallic $\operatorname{Pd}(\sim 335 \mathrm{eV}), 33$ indicating that $\mathrm{Pd}^{2+}$ species is maintained. This $1 \mathrm{eV}$ shift should relate to variation of chemical environment as MOC-16 is surrounded by CZIF-matrix.

Steady-state absorption and emission spectra are effective techniques to characterize electron structure of heterogenous MOC@MOF catalysts. As shown in Figure 5, the absorption spectra of MOC-16 in condensed state (Figure 5A) show two bands at about 280-350 and 400-550 

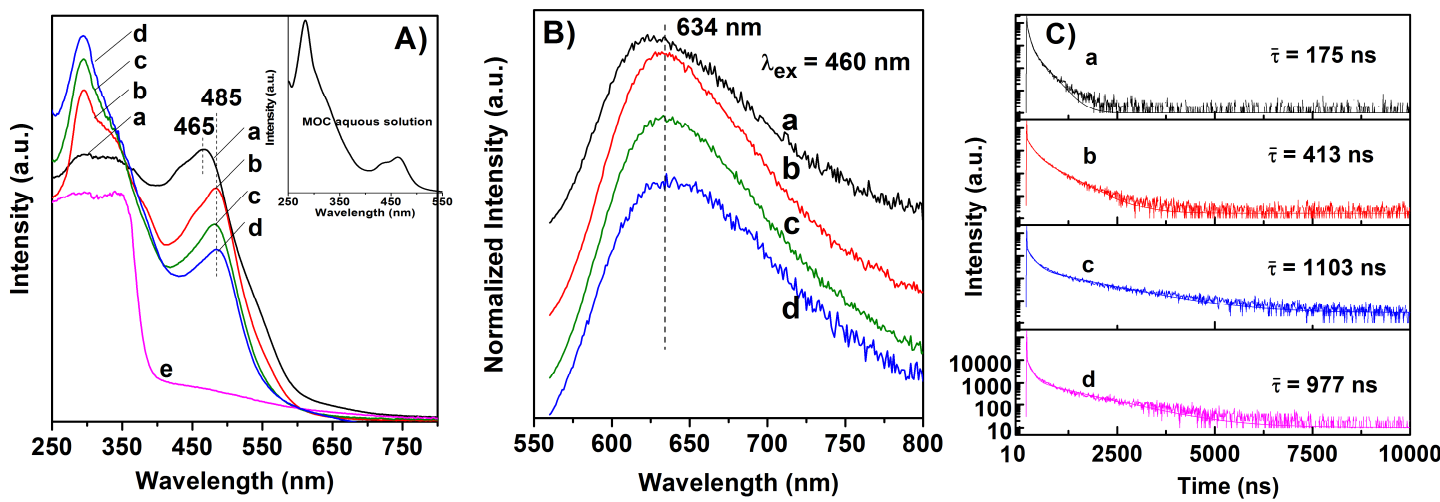

Figure 5. A) UV-visible absorption spectra, B) fluorescence spectra and C) time-resolved emission decay at 634 nm of a) MOC-16, b) MOC-16@ZIF-8, c) MOC-16@CZIF, d) recycled MOC-16@CZIF under CO $_{2}$ atmosphere, and e) recycled MOC-16@CZIF under N2 atmosphere. Insert in A) shows UV-visible absorption spectrum of MOC-16 dissolved in $\mathrm{H}_{2} \mathrm{O}$ solvent.

$\mathrm{nm}$, originated from intra-ligand $\pi-\pi^{*}$ transition and metalto-ligand charge transfer ( ${ }^{1} \mathrm{MLCT}$ of $\mathrm{Phen} \leftarrow \mathrm{Ru}$ ), respectively. ${ }^{5}$ When embedding MOC-16 into ZIF-8 matrix, the first band in UV region is narrowed around $290 \mathrm{~nm}$ and the second band in visible region is red-shifted from 465 to $485 \mathrm{~nm}$, which is similar to spectra profile of MOC-16 dissolved in $\mathrm{H}_{2} \mathrm{O}$ solvent (inset in Figure 5A). This may indicate that the encapsulation of MOC-16 into MOF-matrix is analogue to the dissolution of MOC-16 into solvent environment. For MOC-16@CZIF before and after photocatalytic reaction in $\mathrm{CO}_{2}$ atmosphere, their absorption spectra are similar with those of MOC-16@ZIF-8. However, for the recycled MOC-16@CZIF after reaction in $\mathrm{N}_{2}$ atmosphere, the characteristic bands of MOC-16 are replaced by a sharp band-edge absorption of $\mathrm{ZnO}$ at about $380 \mathrm{~nm}$ along with a tailing peak till $650 \mathrm{~nm}$, in line with the structure degradation of MOC-16@CZIF to a mixture of ZnO and ZIF-8 as revealed by XRD result (Figure 2A-f). In the emission spectra (Figure 5B), a luminescence band centered around $634 \mathrm{~nm}$, relating to $\mathrm{Ru}(\mathrm{Phen})_{3}$-centred triplet ${ }^{3}$ MLCT (metal-ligand charge transfer) state, ${ }^{5}$ is observed for all three samples of MOC-16@ZIF-8, MOC16@CZIF and recycled MOC-16@CZIF under $\mathrm{CO}_{2}$ atmosphere. Compared with condensed state MOC-16, this band is red-shifted several nanometers due to the integration of MOC-16 into MOF-matrix. In contrast, the recycled MOC-16@CZIF under $\mathrm{N}_{2}$ atmosphere displays no luminescence band in the same measurement condition. These absorption and emission spectral results indicate that incorporation of MOC-16 into MOF-matrix does not remarkably alter its ground-state spectroscopic property, only slightly perturbing the energy gap between the lowest excited-state and ground-state. For the recycled MOC16@CZIF after reaction in $\mathrm{N}_{2}$, disappearance of absorption and emission bands belonging to MOC-16 implies that, along with degradation of CZIF-matrix, the embedded MOC16 is released from the matrix into solvent, which is in accordance with a color change from original orange to nearly gray (Figure S7). This observation accounts for the reason that photocatalytic activity of MOC-16@CZIF is dramatically decreased after the first cycle under $\mathrm{N}_{2}$ atmosphere (Figure 1B).

To understand how the high efficiency of MOC-16 as a PMD with multichannel directional electron transfer ${ }^{5}$ is influenced by the MOF-matrix owing to the structural and spatial heterogeneity underlying the interface between
MOC-16 and MOF-matrix, the multi-step-relaxation processes of MOC-16, involving intersystem crossing (ISC) from ${ }^{1}$ MLCT to ${ }^{3}$ MLCT, intraligand charge-transfer (ILCT), ligand-to-metal charge-transfer (LMCT), were investigated by femtosecond transient absorption spectra (Figure S8). The transient absorption of MOC-16@ZIF-8 features in a broad excited-state absorption (ESA) in 530-730 nm region accompanied by a ground-state bleaching (GSB) centered around $490 \mathrm{~nm}$, resembling that of MOC-16 dissolved in DMSO. ${ }^{5}$ For MOC-16@CZIF, a similar GSB profile centered at $490 \mathrm{~nm}$ is observed. The characteristic time constants of both MOC-16@ZIF-8 and MOC-16@CZIF obtained through a global analysis are summarized in Table S4. It is clear that the ISC and ILCT processes occur in a comparable picoseconds time scale with that of MOC-16, although the following LMCT process is slightly sluggish than MOC-16 (535, 630 vs. 122 ps). These results reveal that the dynamics of electron transfer in picosecond domain is not significantly affected when MOC-16 is encapsulated in MOFmatrix, in consistent with the steady-state absorption and emission spectral measurements. Therefore, the efficient and multichannel directional electron transfer from the photosensitizing centers to catalytic centers, characteristic of MOC-type PMD, are well inherited for MOC-16@MOF. On the contrary, the triplet excited-state in nanosecond domain is found to be extremely sensitive to MOF-matrix. Figure $5 \mathrm{C}$ shows emission decay curves monitored at maximum emission wavelength, which are analyzed by double exponential fitting to average lifetimes (Table S5). It turns out that encapsulating MOC-16 into ZIF-8 matrix causes an increase of the average lifetime relating to excited ${ }^{3}$ MLCT state from 175 to 413 ns. When transforming matrix structure from ZIF-8 to carbonate CZIF, a further increase to $1103 \mathrm{~ns}$ is achieved. Similar prolonging emission lifetime of ${ }^{3}$ MLCT state was also observed by Lin et al. when doping $\left[\mathrm{Ir}^{\mathrm{III}}(\mathrm{ppy})_{2}(\mathrm{bpy})\right]^{+}$into rigid MOF framework. ${ }^{19}$ In our case, significant elongation of lifetime may be attributable to inhibition of the non-radiative vibrational relaxation, a competing loss channel with radiative luminescence from ${ }^{3}$ MLCT excited-state to ground state, after incorporating MOC-16 into the rigid MOF-matrix. Transformation of ZIF-8 matrix to carbonate CZIF may further consolidate MOC-16 owing to stronger coordination between $\mathrm{Zn}^{2+}$ and $\mathrm{CO}_{3}{ }^{2-}$ anions, thus the long-lived ${ }^{3}$ MLCT excited states consequently benefits the photocatalytic process owing to MOC-16 heterogenization. 
Another important factor to influence the proton reduction by heterogeneous catalyst is the capability of proton conductivity, as we know, in nature, precisely controlled delivery of protons is critical in hydrogenase enzymes that catalyze $\mathrm{H}_{2}$ production. ${ }^{34} \mathrm{ZIF}-8$ is well known hydrophobic, ${ }^{35-37,38}$ thereof unfavorable to $\mathrm{H}_{2}$ generation. However, when transformed to carbonate CZIF, the MOFmatrix is expected to turn hydrophilic. This is testified by the static contact angle measurements of the surface wettability (Figure S9). MOC-16@ZIF-8 shows strong hydrophobicity with a contact angle of $\sim 139^{\circ}$. By contrast, MOC-16@CZIF is totally water-wettable with zero contact angle (Figure S9), evidently due to its carbonate nature. It was also reported that aquo- and hydroxo-rich MOF nodes could act as proton-relaying to facilitate local proton delivery and/or long-range proton transport. ${ }^{39}$ Based on the superhydrophilic feature, it is supposed that $\mathrm{CO}_{3}{ }^{2-}$ in CZIF-matrix may function as proton relay to manipulate the local chemical environment of confined MOC-16, and guarantees sufficient proximity between proton and catalytic sites to interact with each other for chemical reactions. This may be the pivot point explaining why hydrophobic ZIF-8 matrix does not work on $\mathrm{H}_{2}$ evolution but CZIF-matrix is efficient.

In order to explore the role of $\mathrm{H}_{2} \mathrm{O}$ molecules in photocatalysis, several control experiments with different solvents were performed and summarized in Table S1. In the absence of $\mathrm{H}_{2} \mathrm{O}$, only trace $\mathrm{H}_{2}$ is detected (entries 7 and 8) with $\mathrm{BIH}$ as sacrificial agent under both $\mathrm{N}_{2}$ and $\mathrm{CO}_{2}$ atmosphere, which suggests that $\mathrm{H}_{2} \mathrm{O}$ is indispensable for $\mathrm{H}_{2}$ generation. Considering the wettability of CZIF-matrix, it is speculated that water serves as proton carriers to construct hydrogen bonded networks for proton transfer. Further evidence comes from the control experiment utilizing pure $\mathrm{H}_{2} \mathrm{O}$ as photocatalytic media, where $\mathrm{BIH}$ is undissolved and emulsified together with MOC-16@CZIF catalyst. $\mathrm{H}_{2}$ evolution is still detected under $\mathrm{CO}_{2}$ atmosphere (entry 9) but minimized under $\mathrm{N}_{2}$ atmosphere (entry 10). Taking the CZIF-matrix degradation in absence of $\mathrm{CO}_{2}$ feeding into consideration, it is deduced that protons transfer stems from formation of aqueous carbonic acid under $\mathrm{CO}_{2}$ atmosphere. Considering the $\mathrm{pH}$ value of reaction solution is approximate to 6 under $\mathrm{CO}_{2}$ atmosphere, another control experiment under $\mathrm{N}_{2}$ atmosphere is carried out to clarify the $\mathrm{pH}$ effect, where solution $\mathrm{pH}$ is adjusted by acetic acid to 6 with other conditions equivalent. A significantly low $\mathrm{H}_{2}$ evolution is detected (entry 11), revealing the imperative role of $\mathrm{CO}_{2}$ for protons transfer beyond $\mathrm{pH}$ regulation. It is worthy of noting that, acid conditions except for $\mathrm{CO}_{2}$ mediation will cause dissociation of CZIF-matrix.

In addition to proton transfer, electrical conductivity is also important for heterogeneous photocatalysis concerning electron mobility. The linear I-V characteristics of MOC-16@ZIF-8 exhibits conductivity at the magnitude of $\sim 10^{-10} \mathrm{~S} / \mathrm{cm}$, comparable with that of MOC-16@CZIF (Figure S10, Table S6). Interestingly, when infiltrating sacrificial agent of BIH onto heterogeneous MOC-16@MOF catalysts, the current is significantly enhanced with conductivity increasing by one order of magnitude to $\sim 10^{-9}$ $\mathrm{S} / \mathrm{cm}$, of which MOC-16@CZIF displays triple-fold conductivity compared with MOC-16@ZIF-8 $\left(3.23 \times 10^{-9} v s\right.$. $1.06 \times 10^{-9} \mathrm{~S} / \mathrm{cm}$ ). It had been reported that the redoxactive guest molecules are effective to improve conductivity of a host material. ${ }^{40,41}$ In this case, BIH may behave as an electron donor with sufficient reducing power in solution and solid state, thus inducing free charge carriers within heterogenous MOC-16@MOF catalysts via charge-transfer interaction to promote conductivity.

\section{CONCLUSIONS}

In summary, an MOC-16 based PMD with well-organized multiple photosensitizers and catalyzers has been successfully incorporated into an MOF-matrix via a coordination-assisted secondary assembly process followed by in-situ transformation into carbonate CZIFmatrix. The rigid CZIF-matrix isolates MOC-16 PMDs from each other in coordination interspace while maintaining their effective photophysical and photochemical features. This heterogenized MOC-16@CZIF photocatalyst can survive in ambient reaction condition in the presence of $\mathrm{H}_{2} \mathrm{O}$ and $\mathrm{CO}_{2}$, preventing catalyst from deactivation and degradation. Moreover, synergistic effect is endowed for such MOC@MOF via structural hetereogenity, which renders long-lived excited-state electron in MOC-16 to microsecond order of magnitude. The hydrophilic character of $\mathrm{CO}_{3}{ }^{2-}$ in CZIF-matrix assists in proton delivery to proximal catalytic sites, utilizing $\mathrm{H}_{2} \mathrm{O}$ as proton carriers. The local electron mobility is also boosted by reducing BIH acting as charge carriers, favorable for efficient $\mathrm{H}_{2}$ production. Therefore, the integrated MOC-16@CZIF photocatalyst in this work presents a unique example to combine homogeneous PMDs with MOF-derived materials, giving rise to a heterogenization approach to incorporate molecular catalysts into MOF-matrix to engender appropriate microenvironment to mimic structural and functional features of nature photosystem, and circumvent the intrinsic vulnerability of molecular photocatalyts to achieve efficient and practical photo-conversion.

\section{EXPERIMENTAL SECTION}

Synthesis of MOC-16@ZIF-8: Sample was prepared by a procedure similar to that described for ZIF-8. The encapsulation of MOC-16 into ZIF-8 matrix was carried out by mixing a certain volume of pristine MOC-16 solution with $100 \mu \mathrm{L} \mathrm{Zn}\left(\mathrm{NO}_{3}\right)_{2}$ aqueous solution $(0.01462 \mathrm{~g}, 0.05$ $\mathrm{mol} / \mathrm{L}$ ). After ultrasonic dispersion for $30 \mathrm{~min}$, the mixture was rapidly injected into $1 \mathrm{~mL}$ MeIm aqueous solution $(0.2838 \mathrm{~g}, 3.5 \mathrm{~mol} / \mathrm{L})$ with a molar ratio of $\mathrm{Zn}^{2+}$ to MeIm being 1:70 under vigorous stirring. After a 30 min reaction, the resulting precipitate was centrifuged, washed, and vacuum dried at $50{ }^{\circ} \mathrm{C}$ to get orange powder.

Synthesis of MOC-16@CZIF: 200 mg MOC-16@ZIF-8 powder was dispersed in $1.5 \mathrm{~mL}$ deionized (DI) water under vigorous stirring, then sealing into a $40 \mathrm{~mL}$ glass vial with bubbling $\mathrm{CO}_{2}$ continuously. After stirring for $2 \mathrm{~h}$ at room temperature, the product was collected by centrifuging, washed with DMSO, MeCN and DI water for several times, and then vacuum dried at $65^{\circ} \mathrm{C}$ for $48 \mathrm{~h}$. CZIF was obtained in a similar way. The noble metal contents of $\mathrm{Pd}$ and $\mathrm{Ru}$ were quantitated with inductively coupled plasma-atomic emission spectrometry (ICP-AES) as 0.03 and $0.04 \mathrm{wt} \%$, respectively.

Photocatalytic proton reduction: Hydrogen production experiments were carried out using a $40 \mathrm{~mL}$ closed glass 
vial with magnetic stirring. The amount of produced $\mathrm{H}_{2}$ was analyzed using an off-line gas chromatography (FuLi Analytical Instrument Co., Ltd, GC9790 plus) equipped with a thermal conductivity detector and a $\mathrm{N}_{2}$ carrier. Typically, $1 \mathrm{mg}$ powder sample was suspended in $5 \mathrm{~mL}$ mixed solvent of $\mathrm{H}_{2} \mathrm{O}$ and $\mathrm{MeCN}(\mathrm{v} / \mathrm{v}=2 / 3)$ in the presence of $14 \mathrm{mg}$ sacrificial agent of 1,3-dimethyl-2-phenyl-2,3-dihydro-1 $\mathrm{H}$ benzimidazole (BIH). The light source was a $300 \mathrm{~W}$ Xe lamp (PLS-SXE-300C, Beijing Perfect light) supplying the visible light $(\lambda>420 \mathrm{~nm})$ by using a $420 \mathrm{~nm}$ cut-off filter. In recycle experiment, BIH solid powder was directly added into the previous reaction solution to restart the following cycles.

Transient absorption measurement: It was performed by equipping a regeneratively amplified Ti:Sapphire laser source (Coherent Legend, $800 \mathrm{~nm}, 150 \mathrm{fs}, 5 \mathrm{~mJ}$ per pulse, and $1 \mathrm{kHz}$ repetition rate) and Helios (Ultrafast Systems LLC) spectrometers. Portion of the $800 \mathrm{~nm}$ output $(75 \%)$ pulse was frequency-doubled in a $\mathrm{BaB}_{2} \mathrm{O}_{4}$ (BBO) crystal, which could generate $400 \mathrm{~nm}$ pump light, meanwhile the remaining portion of the output was concentrated into a sapphire window to produce white light continuum (420$780 \mathrm{~nm}$ ) probe light. The $400 \mathrm{~nm}$ pump beam was formed from part of the $800 \mathrm{~nm}$ output pulse from the amplifier and its power was adjusted by a range of neutral-density filters. The pump beam was focused at the sample with a beam waist of about $\sim 360 \mu \mathrm{m}$ and the power intensity was fixed at $14 \mu \mathrm{J} \mathrm{cm}^{-2}$. A mechanical chopper was employed to modulate the pump repetition frequency to $1 / 2$ the probe repetition rate. The probe pulse was recorded using a fiber optics-coupled multichannel spectrometer and the optical path in samples was $5 \mathrm{~mm}$.

\section{ASSOCIATED CONTENT}

\section{Supporting Information}

The Supporting Information is available free of charge on the ACS Publications website. Experimental details, materials characterization, supplementary data.

\section{AUTHOR INFORMATION}

\section{Corresponding Authors}

*shijying@mail.sysu.edu.cn

*cesscy@mail.sysu.edu.cn

Notes

The authors declare no competing financial interest.

\section{ACKNOWLEDGEMENTS}

We gratefully acknowledge the financial support from the NSFC Project (21875293, 21821003, 21890380, 21720102007), Local Innovative and Research Teams Project of Guangdong Pearl River Talents Program (2017BT01C161), the NSF of Guangdong Province (2016A030313268), the STP Project of Guangzhou (201804010386) and the Fundamental Research Funds for the Central Universities (17lgzd18). We thank V. Lukyanchenko for assistance with TA data collection.

\section{REFERENCES}

(1) Zhang, B.; Sun, L. Artificial photosynthesis: opportunities and challenges of molecular catalysts. Chemical Society Reviews 2019, 48, 2216-2264.

(2) Guo, S.; Chen, K.-K.; Dong, R.; Zhang, Z.-M.; Zhao, J.; Lu, T.-B. Robust and Long-Lived Excited State Ru(II) Polyimine Photosensitizers Boost Hydrogen Production. ACS Catalysis 2018, 8, 8659-8670.
(3) Shi, J.; Cui, H. n.; Liang, Z.; Lu, X.; Tong, Y.; Su, C.; Liu, H. The roles of defect states in photoelectric and photocatalytic processes for ZnxCd1-xS. Energy \& Environmental Science 2011, 4, 466-470.

(4) Manbeck, G. F.; Fujita, E.; Brewer, K. J. Tetra- and Heptametallic Ru(II), Rh(III) Supramolecular Hydrogen Production Photocatalysts. Journal of the American Chemical Society 2017, 139, 7843-7854.

(5) Chen, S.; Li, K.; Zhao, F.; Zhang, L.; Pan, M.; Fan, Y.-Z.; Guo, J.; Shi, J.; Su, C.-Y. A metal-organic cage incorporating multiple light harvesting and catalytic centres for photochemical hydrogen production. Nature Communications 2016, 7.

(6) Balzani, V. Photochemical molecular devices. Photochemical \& Photobiological Sciences 2003, 2, 459-476.

(7) Ozawa, H.; Sakai, K. Photo-hydrogen-evolving molecular devices driving visible-light-induced water reduction into molecular hydrogen: structure-activity relationship and reaction mechanism. Chemical Communications 2011, 47, 22272242.

(8) Pfeffer, M. G.; Schaefer, B.; Smolentsev, G.; Uhlig, J.; Nazarenko, E.; Guthmuller, J.; Kuhnt, C.; Waechtler, M.; Dietzek, B.; Sundstroem, V.; Rau, S. Palladium versus Platinum: The Metal in the Catalytic Center of a Molecular Photocatalyst Determines the Mechanism of the Hydrogen Production with Visible Light. Angewandte Chemie-International Edition 2015, 54, 5044-5048.

(9) Li, K.; Zhang, L.-Y.; Yan, C.; Wei, S.-C.; Pan, M.; Zhang, L.; $\mathrm{Su}$, C.-Y. Stepwise Assembly of Pd-6(RuL3)(8) Nanoscale Rhombododecahedral Metal-Organic Cages via Metalloligand Strategy for Guest Trapping and Protection. Journal of the American Chemical Society 2014, 136, 4456-4459.

(10) Zeng, L.; Guo, X.; He, C.; Duan, C. Metal-Organic Frameworks: Versatile Materials for Heterogeneous Photocatalysis. ACS Catalysis 2016, 6, 7935-7947.

(11) Wang, S.; Wang, X. Multifunctional Metal-Organic Frameworks for Photocatalysis. Small 2015, 11, 3097-3112.

(12) Liu, J.; Chen, L.; Cui, H.; Zhang, J.; Zhang, L.; Su, C.-Y. Applications of metal-organic frameworks in heterogeneous supramolecular catalysis. Chemical Society Reviews 2014, 43, 6011-6061.

(13) Zhou, T.; Du, Y.; Borgna, A.; Hong, J.; Wang, Y.; Han, J.; Zhang, W.; Xu, R. Post-synthesis modification of a metal-organic framework to construct a bifunctional photocatalyst for hydrogen production. Energy \& Environmental Science 2013, 6, 3229-3234.

(14) Nepal, B.; Das, S. Sustained Water Oxidation by a Catalyst Cage-Isolated in a Metal-Organic Framework. Angewandte Chemie International Edition 2013, 52, 7224-7227.

(15) Wang, C.; Xie, Z.; deKrafft, K. E.; Lin, W. Doping MetalOrganic Frameworks for Water Oxidation, Carbon Dioxide Reduction, and Organic Photocatalysis. Journal of the American Chemical Society 2011, 133, 13445-13454.

(16) Pullen, S.; Fei, H.; Orthaber, A.; Cohen, S. M.; Ott, S. Enhanced Photochemical Hydrogen Production by a Molecular Diiron Catalyst Incorporated into a Metal-Organic Framework. Journal of the American Chemical Society 2013, 135, 16997-17003.

(17) Fei, H.; Sampson, M. D.; Lee, Y.; Kubiak, C. P.; Cohen, S. M. Photocatalytic CO2 Reduction to Formate Using a Mn(I) Molecular Catalyst in a Robust Metal-Organic Framework. Inorganic Chemistry 2015, 54, 6821-6828.

(18) Nasalevich, M. A.; Becker, R.; Ramos-Fernandez, E. V.; Castellanos, S.; Veber, S. L.; Fedin, M. V.; Kapteijn, F.; Reek, J. N. H.; van der Vlugt, J. I.; Gascon, J. Co@NH2-MIL-125(Ti): cobaloximederived metal-organic framework-based composite for lightdriven H2 production. Energy \& Environmental Science 2015, 8, 364-375.

(19) Wang, C.; deKrafft, K. E.; Lin, W. Pt Nanoparticles@Photoactive Metal-Organic Frameworks: Efficient Hydrogen Evolution via Synergistic Photoexcitation and Electron Injection. Journal of the American Chemical Society 2012, 134, 7211-7214.

(20) Kim, D.; Whang, D. R.; Park, S. Y. Self-Healing of Molecular Catalyst and Photosensitizer on Metal-Organic Framework: Robust Molecular System for Photocatalytic H2 
Evolution from Water. Journal of the American Chemical Society 2016, 138, 8698-8701.

(21) Sasan, K.; Lin, Q.; Mao, C.; Feng, P. Incorporation of iron hydrogenase active sites into a highly stable metal-organic framework for photocatalytic hydrogen generation. Chemical Communications 2014, 50, 10390-10393.

(22) Lan, G.; Zhu, Y.-Y.; Veroneau, S. S.; Xu, Z.; Micheroni, D.; Lin, W. Electron Injection from Photoexcited Metal-Organic Framework Ligands to $\mathrm{Ru}_{2}$ Secondary Building Units for VisibleLight-Driven Hydrogen Evolution. Journal of the American Chemical Society 2018, 140, 5326-5329.

(23) Majewski, M. B.; Peters, A. W.; Wasielewski, M. R.; Hupp, J. T.; Farha, O. K. Metal-Organic Frameworks as Platform Materials for Solar Fuels Catalysis. ACS Energy Letters 2018, 3, 598-611.

(24) Lee, Y.; Kim, S.; Kang, J. K.; Cohen, S. M. Photocatalytic $\mathrm{CO} 2$ reduction by a mixed metal $(\mathrm{Zr} / \mathrm{Ti})$, mixed ligand metalorganic framework under visible light irradiation. Chemical Communications 2015, 51, 5735-5738.

(25) Luo, Y.; Fan, S.; Yu, W.; Wu, Z.; Cullen, D. A.; Liang, C.; Shi, J.; Su, C. Fabrication of Au-25(SG)(18)-ZIF-8 Nanocomposites: A Facile Strategy to Position Au-25(SG)(18) Nanoclusters Inside and Outside ZIF-8. Advanced Materials 2018, 30.

(26) Li, L.; Xiang, S. L.; Cao, S. Q.; Zhang, J. Y.; Ouyang, G. F.; Chen, L. P.; Su, C. Y. A synthetic route to ultralight hierarchically micro/mesoporous Al(III)-carboxylate metal-organic aerogels. Nature Communications 2013, 4, 9.

(27) Tsuruoka, T.; Furukawa, S.; Takashima, Y.; Yoshida, K.; Isoda, S.; Kitagawa, S. Nanoporous Nanorods Fabricated by Coordination Modulation and Oriented Attachment Growth. Angewandte Chemie International Edition 2009, 48, 4739-4743.

(28) Mottillo, C.; Friščić, T. Carbon Dioxide Sensitivity of Zeolitic Imidazolate Frameworks. Angewandte Chemie International Edition 2014, 53, 7471-7474.

(29) Park, K. S.; Ni, Z.; Cote, A. P.; Choi, J. Y.; Huang, R.; UribeRomo, F. J.; Chae, H. K.; O'Keeffe, M.; Yaghi, O. M. Exceptional chemical and thermal stability of zeolitic imidazolate frameworks. Proceedings of the National Academy of Sciences of the United States of America 2006, 103, 10186-10191.

(30) Huang, X. C.; Lin, Y. Y.; Zhang, J. P.; Chen, X. M. Liganddirected strategy for zeolite-type metal-organic frameworks: zinc(II) imidazolates with unusual zeolitic topologies. Angewandte Chemie 2006, 45, 1557-1559.

(31) Morgan, D. J. Resolving ruthenium: XPS studies of common ruthenium materials. Surface and Interface Analysis 2015, $47,1072-1079$.
(32) Shchukarev, A. V.; Korolkov, D. V. XPS Study of group IA carbonates. Central European Journal of Chemistry 2004, 2, 347362.

(33) Arrigo, R.; Schuster, M. E.; Xie, Z.; Yi, Y.; Wowsnick, G.; Sun, L. L.; Hermann, K. E.; Friedrich, M.; Kast, P.; Hävecker, M.; Knop-Gericke, A.; Schlögl, R. Nature of the N-Pd Interaction in Nitrogen-Doped Carbon Nanotube Catalysts. ACS Catalysis 2015, 5, 2740-2753.

(34) Helm, M. L.; Stewart, M. P.; Bullock, R. M.; DuBois, M. R.; DuBois, D. L. A Synthetic Nickel Electrocatalyst with a Turnover Frequency Above 100,000 $\mathrm{s}<$ sup $>-1<$ /sup $>$ for $\mathrm{H}<$ sub $>2</$ sub $>$ Production. Science 2011, 333, 863-866.

(35) Sann, E. E.; Pan, Y.; Gao, Z.; Zhan, S.; Xia, F. Highly hydrophobic ZIF-8 particles and application for oil-water separation. Separation and Purification Technology 2018, 206, 186-191.

(36) Zhang, K.; Lively, R. P.; Dose, M. E.; Brown, A. J.; Zhang, C.; Chung, J.; Nair, S.; Koros, W. J.; Chance, R. R. Alcohol and water adsorption in zeolitic imidazolate frameworks. Chemical Communications 2013, 49, 3245-3247.

(37) Küsgens, P.; Rose, M.; Senkovska, I.; Fröde, H.; Henschel, A.; Siegle, S.; Kaskel, S. Characterization of metal-organic frameworks by water adsorption. Microporous and Mesoporous Materials 2009, 120, 325-330.

(38) Ortiz, A. U.; Freitas, A. P.; Boutin, A.; Fuchs, A. H.; Coudert, F.X. What makes zeolitic imidazolate frameworks hydrophobic or hydrophilic? The impact of geometry and functionalization on water adsorption. Physical Chemistry Chemical Physics 2014, 16, 9940-9949.

(39) Hod, I.; Deria, P.; Bury, W.; Mondloch, J. E.; Kung, C.-W.; So, M.; Sampson, M. D.; Peters, A. W.; Kubiak, C. P.; Farha, O. K.; Hupp, J. T. A porous proton-relaying metal-organic framework material that accelerates electrochemical hydrogen evolution. Nature Communications 2015, 6, 8304.

(40) Talin, A. A.; Centrone, A.; Ford, A. C.; Foster, M. E.; Stavila, V.; Haney, P.; Kinney, R. A.; Szalai, V.; El Gabaly, F.; Yoon, H. P.; Léonard, F.; Allendorf, M. D. Tunable Electrical Conductivity in Metal-Organic Framework Thin-Film Devices. Science 2014, 343, 66-69.

(41) Sun, L.; Campbell, M. G.; Dincă, M. Electrically Conductive Porous Metal - Organic Frameworks. Angewandte Chemie International Edition 2016, 55, 3566-3579. 


\section{Table of Contents}

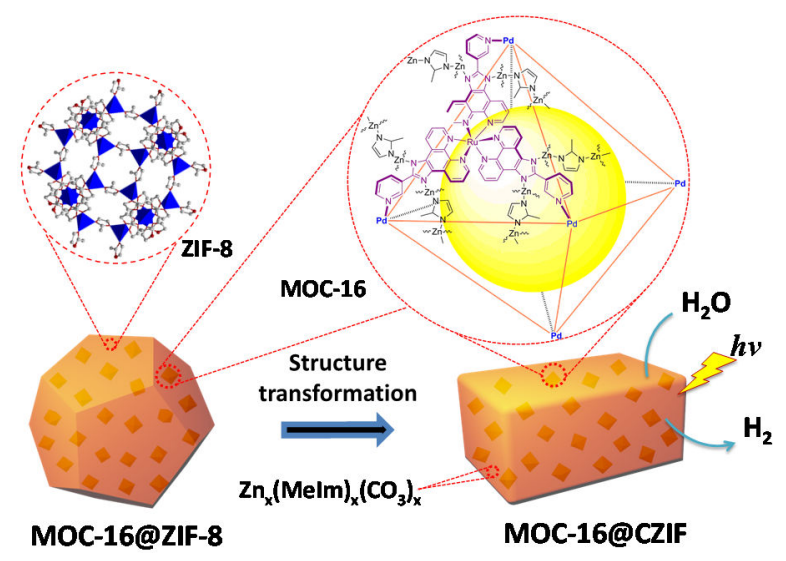

